\title{
Metabolic syndrome
}

\section{Opinion}

In 2015 the incidence of Diabetes mellitus is increasing due to the current life style. At present the incidence is one in 11 adult patients. 92 to $95 \%$ of patients are Type 2 Diabetes Mellitus which is associated with insulin pea and insulin resistance. The incidence of metabolic syndrome is $25 \%$. But at the age of 40 years the incidence becomes $40 \%$ and at $60 y e a r s$ it reaches to $60 \%$. The fast progress in incidence of metabolic syndrome is due to current life style which includes Dietary habits, lack of exercise, smoking, sedentary life style, stress, psychosomatic disorders, alcohol and diet rich in free fatty acids, omega 6 fatty acids and high saturated fatty acids and recycled oil with food having high glycaemic index and dairy products.

\section{Components of metabolic syndrome are}

i. Truncal obesity more than $40 \mathrm{inch}$, in male and $35 \mathrm{inch}$, in females.

ii. High TG more than $150 \mathrm{mg} \%$.

iii. Low HDL less than $40 \mathrm{mg} \%$.

iv. High BP more than $130 / 85 \mathrm{~mm}$ of $\mathrm{Hg}$.

v. Fasting sugar more than $110 \mathrm{mg}$.

Any three of the above will be good enough to lable the person as having metabolic syndrome. Out of these Central obesity should be one of the three components. Polycystic ovary disease, hyperuricemia, acanthosis nigricans, pro inflammatory conditions, decreased fibrinolytic activity are associated factors related to metabolic syndrome. Body mass index is lee important than truncal obesity as with lesser than 25 BMI people are having metabolic syndrome particularly in Asian and South East Asian population as compared to Western or European population. Males are affected more than females. But the prognosis is very bad in females than males. Smoking also plays an important role along with Genetic predisposition. In proinflammatory status role of cytokines, resistins, CRP, fibrinogen TNF alpha, Pasminogen Activator Inhibitor1, decrease adiponectin level is important. Decrease level of brown fat is also important. Hormonal disturbances like decrease level of growth hormone, increased RAAS activity, increase level of cortisol also play their role in causing hypertension and insulin resistance.

\section{Pathophysiology}

Increased level of free fatty acids will have bad effect on liver, adipose tissue and muscles and pancreases. FFA is responsible for
Volume 4 Issue 4 - 2017

\author{
Jayesh V Trivedi \\ Head of Department and Professor of Medicine, Gujarat Adani
} Institute of Medical Science, India

Correspondence: Jayesh V Trivedi, Head of Department and Professor of Medicine, Gujarat Adani Institute of Medical Science, Bhuj, Gujarat, India, Email drjvtrivedi@rediffmail.com

Received: June 06, 2017| Published: June 13,2017

alteration in carbohydrate, fat and protein metabolism. This will further destroy pancreatic beta cells and will increase gluconeogenesis. Moreover adipose tissues and muscles become resistant to uptake carbohydrate resulting in to insulin resistance.

\section{Prevention and treatment}

Avoid smoking, Lifestyle modifications like regular 40min exercise 6days in a week with diet intake where fibers, are more and less in saturated fatty acids and low calories. Small frequent diet containing salads, fruits are advocated. Restriction of salt intake and restriction of Alcohol intake. Weight loss of $10 \%$ of body weight in 6 months is advocated. Avoid junk food. Metformin and pioglitazones are recommended with statins and anti hypertensive drugs and small dose aspirin in patients having atherosclerosis. Life style modifications have a very big role to play in controlling and preventing the prevalence of disease and its incidence and their complications. ${ }^{1-3}$

\section{Acknowledgements}

None.

\section{Conflict of interest}

The author declares no conflict of interest.

\section{References}

1. Metabolic syndrome criteria, symptoms, diet \& treatment-medicine net.

2. Metabolic syndrome-health line.

3. Metabolic syndrome:practice essentials, background, pathophysiology. 